\title{
Fact checking durante la COVID-19: análisis comparativo de la verificación de contenidos falsos en España e Italia
}

\author{
Fact checking during COVID-19: a comparative analysis of the \\ verification of false contents in Spain and Italy
}

\author{
Peña Ascacíbar, G., Bermejo Malumbres, E. y Zanni, S. ${ }^{1}$ \\ Recibido: 15-08-2020 - Aceptado: 27-01-2021 \\ https://doi.org/10.26441/RC20.1-2021-A11
}

\begin{abstract}
RESUMEN: Con la propagación de la COVID-19 alrededor del mundo, también se difunden asociados a la misma una gran cantidad de bulos o noticias falsas y descontextualizadas. En este tiempo los estudios realizados respecto a dicha temática se han focalizado principalmente en la investigación de casos uniterritoriales. Por eso consideramos pertinente ampliar el espectro y observar el comportamiento más allá de un solo país. En concreto, en el trabajo que se presenta se recoge un análisis comparativo entre España e Italia sobre los contenidos falsos y los diversos elementos que han intervenido en su difusión a través de diferentes medios de comunicación y redes digitales durante los primeros meses del nuevo tipo de coronavirus en Europa. Para ello hemos acudido a las plataformas de fact checking Maldita.es y Open. Con toda la información recopilada, hemos generado una base de datos propia sistematizando los siguientes cinco elementos: tipología, soporte de difusión, formato, temáticas generales y ejes discursivos. Con el objetivo de contar con una muestra adecuada, hemos seleccionado a tal efecto un período que comprende desde la constancia de los primeros casos a finales de enero hasta los últimos días de mayo de 2020. La investigación realizada respecto a esos cinco meses nos ha permitido poder desarrollar un estudio con el que comprobar cuantitativa y cualitativamente cómo las características discursivas de los contenidos falsos relacionados con la pandemia se han desarrollado con formas y tiempos diferentes en cada uno de los territorios aunque también compartiendo una serie de temáticas similares entre ambos.
\end{abstract}

Palabras clave: coronavirus; COVID-19; desinformación; España; noticias falsas; fact checking; Italia; Maldita.es; narrativas discursivas; Open.

ABSTRACT: With the spread of COVID-19 around the world, a large number of hoaxes or false and out of context news are also spreading. In the moment, the studies that have been carried out regarding the topic have mainly focused on single-territory research. For this reason, we consider it pertinent to widen the spectrum and observe the behaviour of more than just one country. More specifically, the present study compiles a comparative analysis between Spain and Italy regarding fake contents and the diverse elements that have come into play in the media during the first months of the new type of coronavirus in Europe. To do this, we have used the fact checking platforms Maldita.es and Open. Once the information was collected, we created our own database systematizing the following five elements:

\footnotetext{
${ }^{1}$ Gonzalo Peña Ascacíbar es Doctor e investigador en Aspectos Teóricos, Estructurales y Éticos de la Comunicación de Masas por la Universidad Complutense de Madrid. gonzalo.pena@ulepicc.es https://orcid.org/0000-0001$\underline{5525-4153}$

Eloy Bermejo Malumbres es Doctor en Historia del Arte por la Universidad de Zaragoza y en Historia de la Arquitectura por la Università degli Studi di Palermo e investigador en el Instituto de Estudios Riojanos, Logroño (La Rioja). ebermejo@unizar.es https://orcid.org/0000-0003-2614-6641

Stefano Zanni es Licenciado en Filosofía e investigador (Estudios de Humanidades) por la Università degli Studi di Milano (Italia) y profesor en el Liceo Científico Dr. Miguel Canela Lázaro (República Dominicana). stefano.zanni@ studenti.unimi.it https://orcid.org/0000-0002-6923-6666
} 
type, broadcasting platform, format, general topic, and discursive axis. With the objective of having an adequate sample, we have selected a period beginning with the emergence of the first cases at the end of January until the end of May 2020. The research carried out over these five months has allowed us to develop a study with which to quantitatively and qualitatively verify how the discursive characteristics of false contents related to the pandemic have developed in different ways and times in each of the territories, while also sharing a series of similar topics between both.

Keywords: coronavirus; COVID-19; disinformation; Spain; fake news; fact checking; Italy; Maldita.es ; discursive narratives; Open.

\section{Introducción}

A finales del año 2019 China informaba de la detección en Wuhan de un número de casos de neumonía en personas con ciertas características anómalas. Días más tarde, ya entrado el año 2020, desde el mismo país se confirmaba al mundo que esto estaba relacionado con el brote del virus SARS-CoV-2, que se propagaba de persona a persona y que provocaba a nivel mundial la llamada enfermedad COVID-19.

La pandemia provocó una gran cantidad de informaciones desde el inicio del año hasta mediados de marzo, detectandose más de 240 millones de mensajes relacionados con el conocido a nivel general como coronavirus y siendo compartidos a nivel mundial a través de las redes digitales y los medios de comunicación, alcanzando un promedio de 3,08 millones de mensajes diarios (Larson, 2020).

En un mundo global como en el que nos encontramos, la información sobre el brote comenzó a generar diferentes especulaciones y teorías sobre sus orígenes, así como una gran cantidad de noticias falsas, manipulaciones y bulos de todo tipo sobre la enfermedad. La gran repercusión del coronavirus lo ha colocado como un hecho que merece ser estudiado a nivel comunicativo, sobre todo en cuanto a la generación de contenidos falsos y su influencia en la desfiguración de la percepción informativa así como una distorsión (Mayo-Cubero, 2020) de la realidad en un escenario proclive por su magnitud para ello.

Esta convulsión de los escenarios mediáticos y de las redes digitales ha generado ya diversos estudios de relevancia, a los cuales se están uniendo otros incorporando diferentes perspectivas. El impacto de la COVID-19 ha producido una diversidad de fases en el consumo de información durante los primeros meses de la misma donde está teniendo lugar un nivel considerable de alertas falsas y bulos, provocando, como afirmó la propia Organización Mundial de la Salud, una consecuente "infodemia" debido a la sobreabundancia de información no fiable al respecto.

Es por ello que con el presente estudio pretendemos analizar las diferencias y similitudes en la difusión de los contenidos falsos entre dos de los países más golpeados y afectados por el coronavirus en Europa, como son España e Italia. A través del proceso y los resultados podremos comprender los elementos comunicativos que se viralizaron en cada uno de los países y cómo se difundieron y repercutieron en las diferentes esferas sociales.

\section{Marco teóríco}

En situaciones críticas de elevada complejidad y alto riesgo para la vida humana, como resulta el nuevo coronavirus, los ciudadanos y ciudadanas conciben la búsqueda de información y el seguimiento de las noticias como actividades clave. Los contenidos falsos, en un entorno como este, proliferan en múltiples tipos y temáticas, lo que conlleva un mayor peligro al afectar al ámbito de la salud y la seguridad pública. Los estudios recientes (Brennen et al., 2020) al respecto sobre la COVID-19 sugieren que la información falsa o errónea adopta múltiples formas, procede de fuentes variadas y sus afirmaciones son diversas, reconfigurando frecuentemente el contenido verdadero. 
En ese proceso la incertidumbre, el miedo y la preocupación se convierten en un perfecto caldo de cultivo para la desinformación en sus diversas variantes, siendo los contenidos compartidos con gran intensidad. Esto se debe comprender desde una multicausalidad en la que se puede encontrar desde la buena intención a la hora de difundir una serie de datos no comprobados, la conspiración que duda de toda información oficial, el hecho de promover el odio con intencionalidad política, probar la viralidad y el impacto de un reto o hasta la generación de caos y desestabilización en busca del interés particular (López-Borrull, 2020).

Según se desprende de una investigación realizada en este sentido, "la COVID-19 ha reconectado a las noticias al público menos interesado y más alejado de la información" (Casero-Ripollés, 2020, p. 10), donde, por otro lado, los usuarios y usuarias de redes digitales fueron quienes mayores falsedades descubrieron al respecto.

De este modo, gran parte de las noticias tergiversadas se difunden por redes digitales aprovechando la interconexión y capacidad de convertirse en virales, utilizándose estos espacios asiduamente para generar y extender información errónea, propagar falsas informaciones o datos que no han sido verificados sobre contenidos de salud (Kata, 2012).

A tal efecto, la revista Science publicó un artículo (Lazer et al., 2018) en el que se subraya la preocupación que suscita este fenómeno, el cual ha dejado al descubierto la amplificación de la recepción de noticias afines al pensamiento y creencias propias y la vulnerabilidad de los sujetos, las instituciones y el conjunto de la sociedad frente a la manipulación que terceros pueden efectuar en la era digital.

Estas tendencias han creado un contexto en el que los contenidos falsos e informaciones erróneas pueden atraer a una amplia audiencia (Muñoz-Machado Cañas, 2020). Además de ello, este tipo de informaciones se comparten más que las contrastadas y basadas en evidencias entre los usuarios y usuarias de las redes (Pulido-Rodríguez et al., 2020).

En una situación de cambio en el consumo informativo y viralidad comunicativa como la actual, la verificación ante la desinformación se ha convertido en un elemento fundamental a analizar tanto en el campo académico ${ }^{2}$ como periodístico. La necesidad de atajar este problema ha dado lugar a la consolidación del fact checking, "una operación que aplica técnicas del periodismo de datos para desenmascarar los errores, ambigüedades, mentiras, falta de rigor o inexactitudes de algunos contenidos publicados en los medios" (Ufarte-Ruiz, Peralta-García \& Murcia-Verdú, 2018, p. 734) así como en redes digitales.

Aunque la verificación informativa es una práctica imprescindible en cualquier proceso de producción periodística, en los últimos años esta ha adquirido una nueva dimensión ante la exponencial proliferación de los mensajes falsos o falseados (López-Pan \& Rodríguez-Rodríguez, 2020). La importancia del fact checking se justifica así en la actualidad debido al gran recorrido de las informaciones falsas difundidas, las cuales se ven ampliadas en un escenario como el de la digitalización.

De este modo, se han ido desarrollando con el tiempo diversas plataformas especializadas para aclarar y arrojar luz sobre informaciones construidas de forma no adecuada o falsa, usando para ello técnicas y procedimientos de comprobación rastreando su propagación y alcanzando hasta el origen de dichos contenidos (Vizoso \& Vázquez-Herrero, 2019). Dado el alcance y la gravedad de

\footnotetext{
${ }^{2}$ La detección de noticias falsas, erróneas y bulos en redes y medios se ha convertido en un campo de investigación emergente. Es conveniente así utilizar términos diferentes y asignar el de noticia falsa a aquella que parece ser verdadera y no lo es y el de bulo a comentarios, informaciones o imágenes que no se preocupan por ser considerados noticia (Losada, 2020).
} 
la pandemia de la COVID-19, el fact checking constituye un papel fundamental en identificar los bulos y las noticias falsas y erróneas asociadas al coronavirus.

\section{Objetivos}

Los fenómenos de desorden de la información (Bracciale \& Grisolia, 2020) construyen un mundo artificial, lo cual, sin embargo, da lugar a comportamientos reales y, en ocasiones, hasta peligrosos. Es por ello que en esta investigación el objetivo fundamental es contribuir al análisis del fenómeno respecto a las diferentes formas de producción y difusión de los contenidos falsos y su relación con la distorsión de la realidad.

En este sentido, también según los autores mencionados, el potencial de difusión de una noticia depende tanto de su contenido, en cuanto a lo relacionado con provocar una reacción emocional en el receptor, como de las formas de su propagación y reproducción. Además de ello, también es necesario considerar otros factores extrínsecos como el sesgo de confirmación y el funcionamiento de los algoritmos en las redes digitales.

De este modo, a través de un análisis de fondo y forma de los casos analizados, se quiere evidenciar aquellas características que determinan la probabilidad de que cierto contenido sea recibido a favor, circule y se propague. Estas variables contribuyen a determinar el ciclo de vida de los bulos (Vosoughi, Roy \& Aral, 2018) desde el momento en que se generan, pasando por su grado de incursión en el espacio público hasta su posible desaparición.

Para realizar una primera clasificación de contenido y características de las noticias falsas que se pretenden estudiar, llevaremos a cabo un análisis cuantitativo, categorizando los casos de acuerdo a los criterios expuestos en la metodología. Este análisis nos permitirá destacar los elementos asociados a la difusión de contenidos falsos, los canales de mayor viralidad y los temas que se reproducen con mayor frecuencia.

De acuerdo con esto, en el presente trabajo analizaremos las dinámicas y variantes entre España e Italia, los cuales fueron los primeros países que tuvieron que enfrentar la aparición del virus en Europa. Las medidas que ambos implementaron han representado un laboratorio político y social sin precedentes, inevitablemente acompañado de una gran aprensión ciudadana, así como un gran campo para la investigación.

Al comparar dos arquitecturas culturales y de información diferentes, identificaremos tanto los paralelismos como las divergencias con los resultados obtenidos del análisis cuantitativo. Debido a la novedad y excepcionalidad de los hechos, consideramos que los primeros cinco meses del año 2020 constituyen un marco temporal adecuado para estudiar los procesos en estos dos territorios que hacen que los contenidos falsos se vuelvan virales.

\section{Metodología}

En el presente artículo hemos decidido elaborar una comparativa de las falsas informaciones que han operado en España e Italia respecto al nuevo tipo de coronavirus. Estos han sido los primeros Estados miembros de la Unión Europea que han sufrido sus consecuencias de manera más intensa y, por ello, queremos observar y analizar cómo han influido los componentes informativos y qué impacto han tenido, por un lado, en cada uno y, por otro, entre ellos.

Tomando en cuenta varios estudios realizados al respecto (Salaverría et al., 2020; Casero-Ripollés, 2020), el análisis se ha centrado en identificar el desarrollo de los elementos que intervienen en la propagación de los bulos difundidos en medios de comunicación y redes digitales durante los 
primeros meses de la pandemia de la COVID-19. La variante que hemos considerado conveniente introducir ha sido ampliar el espectro más allá de la caracterización en un solo país, yendo a la relación existente entre dos territorios que, por su cercanía geográfica en la región del Mediterráneo, comparten, a priori, ciertos elementos históricos y culturales similares.

Basándonos en los estudios analíticos realizados al respecto (Vázquez-Herrero, Vizoso \& López-García, 2019; Ufarte-Ruiz, Anzera \& Murcia-Verdú, 2020; Pérez-Curiel y Velasco Molpeceres, 2020) y las consideraciones propias, hemos acudido a dos plataformas de fact checking respectivas para el caso de estudio. En concreto, en el ámbito español, se ha utilizado el medio Maldita.es, mientras que por la parte italiana ha sido el periódico Open y su proyecto 'Fact-checking', al considerar que eran los que mejor se ajustaban a la investigación realizada por su amplia cantidad de análisis de bulos y clasificación de los mismos, ya que ambos forman parte y son miembros de la International Fact-Checking Network dentro de su programa Fighting the Infodemic: The \#CoronaVirusFacts Alliance, promovido por The Poynter Institute ${ }^{3}$.

Maldita.es nace como medio digital sin ánimo de lucro fundado por Clara Jiménez y Julio Montes. Sus ingresos proceden en su mayoría de diferentes becas y alianzas con Facebook, Google así como de colaboraciones con medios y aportaciones individuales a través del crowdfunding. Por su parte, Open es un periódico en línea publicado por Gol, una empresa sin ánimo de lucro fundada por Enrico Mentana. Sus ingresos dependen de las inversiones de Mentana y de los anuncios publicitarios, aceptando también contribuciones voluntarias.

En función de la viralidad y la peligrosidad, ambas plataformas verifican datos y hechos (no opiniones) susceptibles de ser contrastados por un equipo de investigación del posible contenido falso a partir de su origen, el contacto con fuentes primarias y la consulta de fuentes oficiales. No obstante, creemos necesario aclarar que la muestra presentada en este estudio no representa la totalidad de los casos que se difundieron en España e Italia durante el período analizado, sino que son los bulos recogidos y verificados por esos dos espacios.

Con todo ello hemos generado una base de datos propia sistematizando los siguientes cinco elementos: tipología, soporte de difusión, formato, temáticas generales y ejes discursivos. De esta manera, hemos podido vertebrar un análisis que nos ha permitido observar cuantitativa y cualitativamente tanto la relación como las variaciones entre España e Italia.

El caso de estudio comprende un espacio de muestra que va desde finales de enero, mes en el que se recoge el primer bulo en las citadas plataformas, hasta el 31 de mayo. Estos casi cinco meses ofrecen una secuencia temporal adecuada para poder llevar a cabo la investigación de una manera lo más apropiada posible junto a los vectores señalados en el párrafo anterior.

\section{Análisis del caso de estudio}

Tal y como hemos planteado en la metodología, el caso de estudio se basa en el análisis de cinco elementos que participan en la propagación y difusión de contenidos falsos y que abordamos tanto de forma individual como comparada entre España e Italia durante los meses de enero a mayo.

\subsection{Primer elemento: tipología}

Teniendo en cuenta que las informaciones falsas reúnen múltiples categorías, desde el punto de vista práctico del trabajo hemos considerado que era necesario realizar una división de los casos

\footnotetext{
${ }^{3}$ Ver más en https://www.poynter.org/coronavirusfactsalliance/.
} 
en cuatro grupos principales que permitieran ofrecer una visión global lo más completa posible, destacando las siguientes:

- alertas falsas, es decir, aquellas noticias manipuladas que se hacen pasar como verdaderas por organismos y entidades oficiales.

- informaciones erróneas, en las cuales se constata una falta de contexto de los contenidos pero que se difunden con una intencionalidad de veracidad a pesar de resultar falsas.

- mentiras o manipulaciones intencionadas con el objetivo de producir un daño político, social, religioso o sanitario.

- otros, para aquellos tipos de bulos que no encajen en ninguna de las categorías anteriormente mencionadas, tales como perfiles de humor o sucesos extraños.

\section{España}

La propagación de los contenidos informativos falsos causa entre los españoles y españolas una gran desconfianza. Tal y como indican recientes estudios (Negredo, Amoedo, Vara-Miguel, Moreno \& Kaufmann, 2020), el 65\% de los usuarios y usuarias de Internet consultados afirma que entre sus mayores preocupaciones se encuentra no saber diferenciar entre lo que es verdadero o falso en la red.

Hilando con ello, los tipos de elementos examinados en este trabajo se ha distribuido tal y como se observa en el Gráfico 1: de un total de 365 casos analizados, 58 de ellos corresponden al primer grupo de alertas falsas $(15,84 \%), 125$ a la categoría de informaciones erróneas $(34,15 \%)$, un total de 160 a mentiras o manipulaciones $(43,71 \%)$ y 22 a otros $(6 \%)$.

Esto nos permite constatar que los tipos de casos más difundidos en España están relacionados con manipulaciones, sobre todo aquellas que están dirigidas a provocar o causar desestabilización, odio, señalamientos, beneficios políticos y otras que trataremos a continuación con mayor profundidad.

El análisis ha permitido también comprobar la intensidad de propagación de cada una de las categorías a lo largo del período analizado entre enero y mayo. Observamos una mayor cantidad de alertas falsas entre mediados del mes de marzo y abril mientras que las informaciones erróneas mantienen una regularidad pero se concentran, sobre todo, en las primeras semanas de febrero, lo que podría indicar una mayor difusión en estas fechas por la falta de conocimiento sobre el virus.

Mientras, en cuanto a las mentiras, al ser la categoría más numerosa, hay una continuidad durante todo el período aunque comienzan a ser más profusas desde la mitad del mes de marzo. En lo relacionado con las informaciones erróneas, el segundo grupo con mayor cantidad de casos, detectamos una mayor concentración en la etapa inicial analizada, seguramente debido al desconocimiento y la confusión respecto a los primeros momentos de aparición del virus.

\section{Italia}

Por la parte de Italia, hemos analizado 225 casos, registrándose la siguiente distribución respecto a los tipos que se ven en el Gráfico 1: 22 fueron clasificados como alertas falsas (9,77\% del total), 84 como informaciones erróneas $(37,3 \%)$, los pertenecientes a la categoría de mentiras o manipulaciones fueron $115(51,11 \%)$ y 4 aquellos que no encajaban dentro de las clasificaciones anteriores $(1,77 \%)$.

Con la misma tendencia destacada que en el caso de España, en Italia los casos más difundidos fueron aquellos dirigidos a manipular a los destinatarios y, por lo tanto, caracterizados por su intencionalidad en la difusión de contenido informativo falso. Esta tipología de noticia se ha producido 
mayormente con el objetivo de generar confusión y pánico, pero en varias ocasiones manifestaba una finalidad política, acompañada ocasionalmente por tintes discriminatorios o racistas.

Con respecto a la distribución temporal de los diferentes casos, se registra una mayor concentración de alertas falsas entre la segunda mitad de febrero y la primera mitad de marzo. En cambio, las informaciones erróneas alcanzan su cénit en marzo, mientras que luego se observa una disminución. En cuanto a las mentiras, la categoría más numerosa, se registra un pico significativo entre finales de marzo y principios de abril, en correspondencia con el repentino aumento de los casos de coronavirus en Italia.

Gráfico 1. Tipos de contenidos falsos

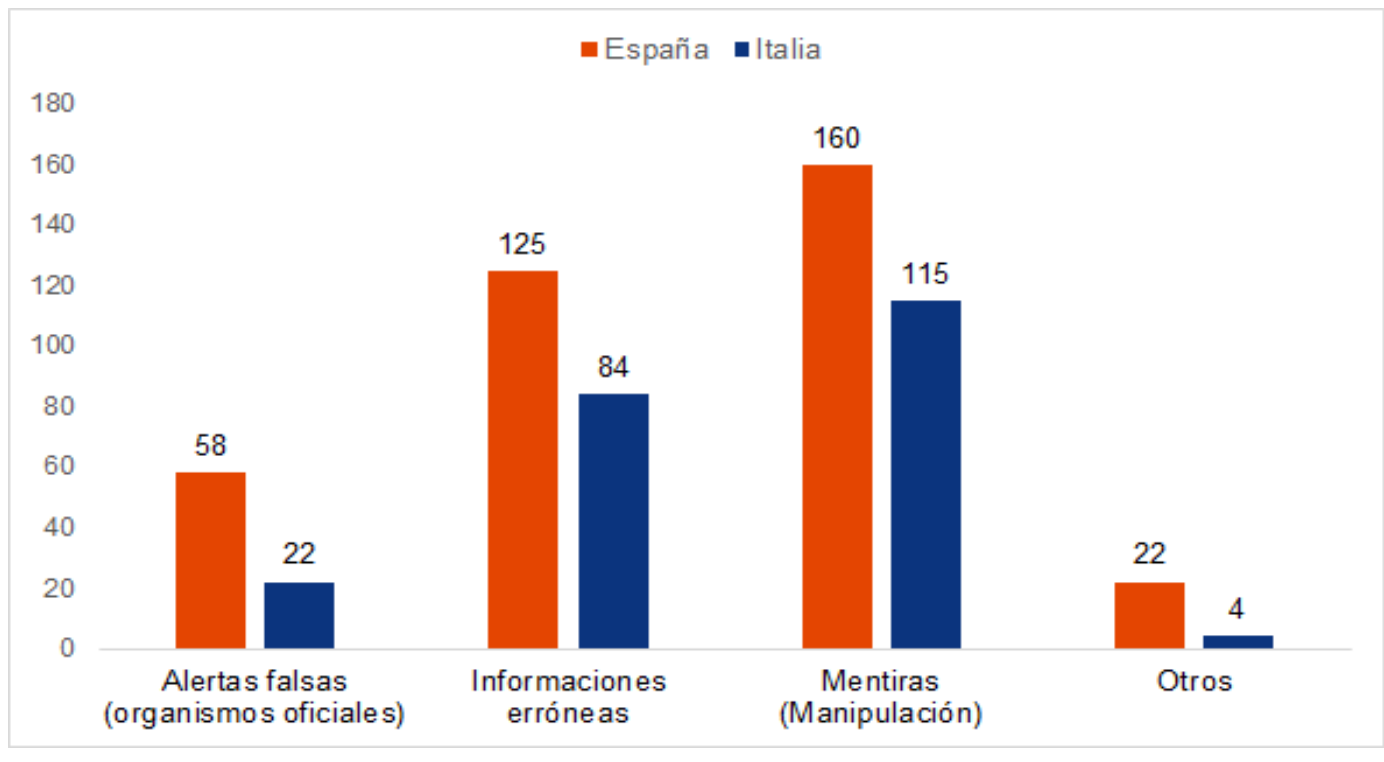

Fuente: Elaboración propia

\subsection{Segundo elemento: soporte de difusión}

La propagación de los contenidos se produjo a través de diferentes canales que hemos creído conveniente agrupar en cinco grupos diferenciados recogidos en el Gráfico 2. De todos ellos, el más específico es el que se centra en la red social WhatsApp, al tratarse de una plataforma donde habitualmente más se viralizan las noticias falsas y que permite, al ser una red de mensajería cerrada, mayor facilidad a la hora de compartirlas entre usuarios.

\section{España}

Durante la pandemia de la COVID-19 se produce un cambio en los hábitos del consumo de información durante el confinamiento. Según los datos del último Digital News Report disponible (Negredo, Amoedo, Vara-Miguel, Moreno \& Kaufmann, 2020), el 75\% de usuarios adultos de noticias online empleó alguna de las redes digitales para conocer novedades o explicaciones sobre el coronavirus, lo cual supuso el incremento de su función informativa en varias de estas plataformas, representando el 42\% para WhatsApp, lo mismo para Facebook, el 30\% para Twitter, el 26\% YouTube y el 21\% Instagram.

En relación también con ello, el $31 \%$ de las personas encuestadas considera que los canales más utilizados para la propagación de bulos se dan en las redes digitales (Facebook, Twitter, Instagram y YouTube), el 25\% señala los medios digitales como sitios web o aplicaciones de noticias y un $20 \%$ a las apps de mensajería instantánea (WhatsApp o Facebook Messenger) como principales canales para la propagación de la desinformación. 
Por lo que respecta al presente estudio, un total de 128 casos fueron difundidos particularmente a través de WhatsApp, lo que supone que esta plataforma abarque aproximadamente un $35 \%$ del conjunto analizado. Por su parte, el segundo grupo es el de mayor difusión, al concentrar mayor cantidad de redes digitales, entre las que cabe destacar Facebook, Twitter e Instagram, con 131 bulos, casi un 36\%, mientras que YouTube, que se centra en la difusión de contenidos por vídeo, ocupa un total de 44 bulos, el $12 \%$.

La siguiente categoría recoge 14 casos que se transmitieron a través de diferentes webs de medios de comunicación y que representan solamente un 3,82\% del total. También se observa si la propagación se producía al mismo tiempo en redes digitales y medios de comunicación, lo que arrojó 40 noticias falsas, alrededor de un $11 \%$. En último lugar aparecen diversas plataformas digitales, diferentes a las mencionadas anteriormente, cuyo número es el más bajo con 8 , representando un $2,18 \%$ del total.

El análisis muestra así una difusión regular y constante en el tiempo de cada uno de los soportes estudiados aunque las redes digitales son mucho más preponderantes que los medios de comunicación, siendo el principal espacio de difusión de los casos considerados.

\section{Italia}

En Italia hubo 46 episodios de contenidos difundidos a través de WhatsApp, con un porcentaje del $20,44 \%$ del total, confirmándose esta aplicación como el medio en solitario donde más se contribuye a la propagación de casos analizados. El segundo grupo, que contiene las demás redes sociales, es el más relevante con 83 casos (36,88\%). En concreto, 51 de los bulos, el 22,6\%, se distribuyeron entre Facebook, Instagram y Twitter, mientras que sólo Youtube reúne un 14,22\% (32 casos encontrados).

La siguiente categoría incluye todos los ítems publicados en medios de comunicación, contando con 47 casos $(20,88 \%)$. Por último, en cuanto a las noticias difundidas tanto en los medios como en las redes digitales, detectamos 49 casos, correspondientes al 21,77\% del total. Por otra parte, no hubo casos que no fueran atribuibles a ninguna de las categorías anteriores, por lo que el último grupo no cuenta con registros.

Gráfico 2. Soporte de difusión

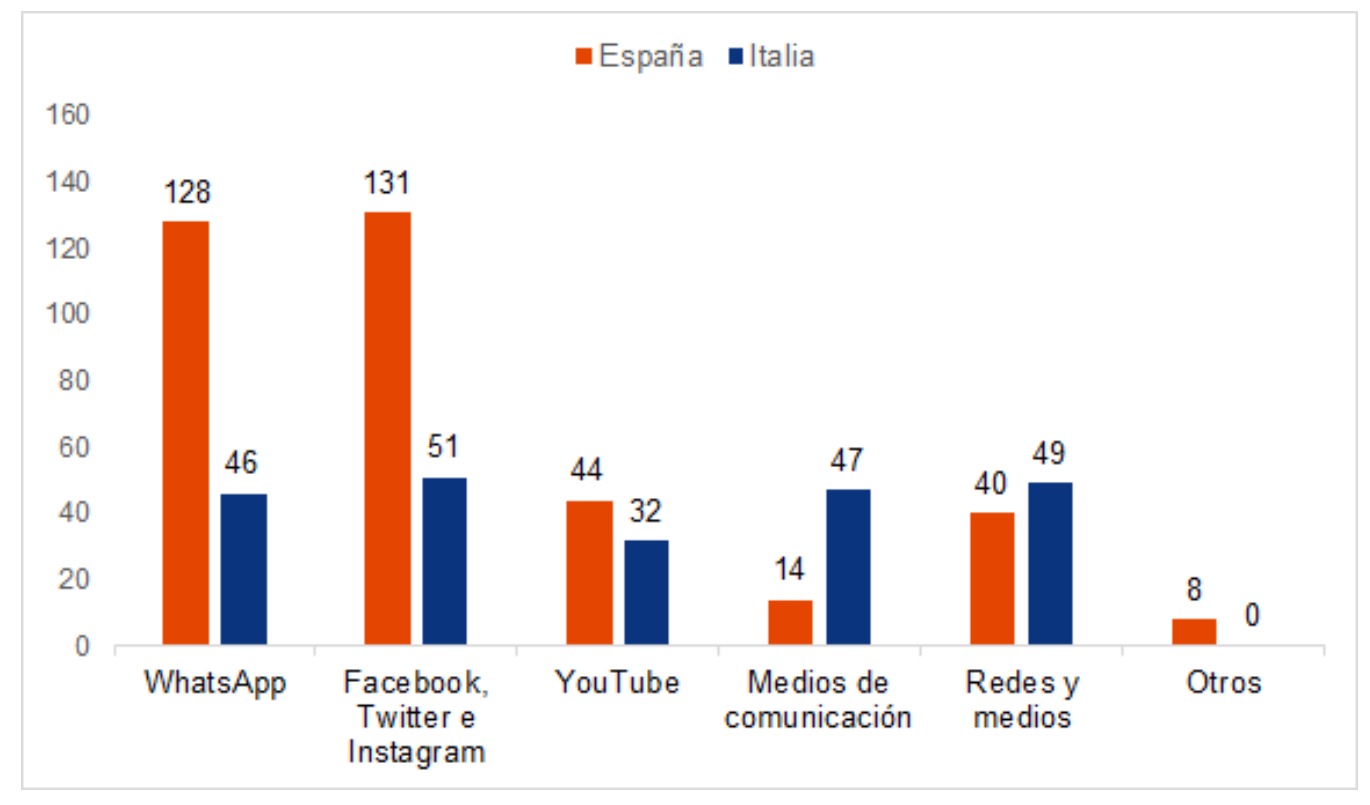

Fuente: Elaboración propia 
Podemos observar que la mayoría de los casos están concentrados en el período comprendido entre marzo y abril, independientemente del medio seleccionado. Los resultados muestran también que los soportes predominantes de difusión de los bulos son las redes digitales.

\subsection{Tercer elemento: formato}

Respecto a los formatos comunicativos en los cuales se difunden los contenidos, podemos observar en el Gráfico 3 cómo la mayor parte de los mismos cuenta con texto, tal vez el formato más sencillo de generar y que permite distribuirse más fácilmente en redes digitales y medios de comunicación, además de formar parte combinada con otros formatos como imágenes o vídeos. Incluso cuando esto sucede, el texto es el principal elemento que suele utilizarse para la conformación del bulo, descontextualizando completamente la información.

\section{España}

La cantidad de casos que contiene solamente texto en el territorio español es de 110 (30,05\%), una proporción muy similar a aquellos que comprenden texto y van acompañados por algún tipo de imagen, que son $112(30,60 \%)$. Un porcentaje menor contiene formatos como el vídeo con 62 casos $(16,93 \%)$ y solamente imagen con $61(16,66 \%)$. El último lugar está ocupado por los audios, de los cuales hemos identificado un total de $20(5,46 \%)$.

\section{Italia}

En Italia los tipos analizados con formato únicamente textual han representado el grupo más importante con 96 casos $(42,66 \%)$. El uso de vídeos también fue muy consistente, incluyendo este grupo aproximadamente una cuarta parte de los casos analizados con 56 noticias ( $24,88 \%$ del total). Los formatos imagen e imagen con texto han tenido menos incidencia, registrando ambos 28 casos (aproximadamente el 12\%), mientras que el formato audio, todavía menos utilizado, se encontró tan solamente en 17 casos $(7,55 \%)$

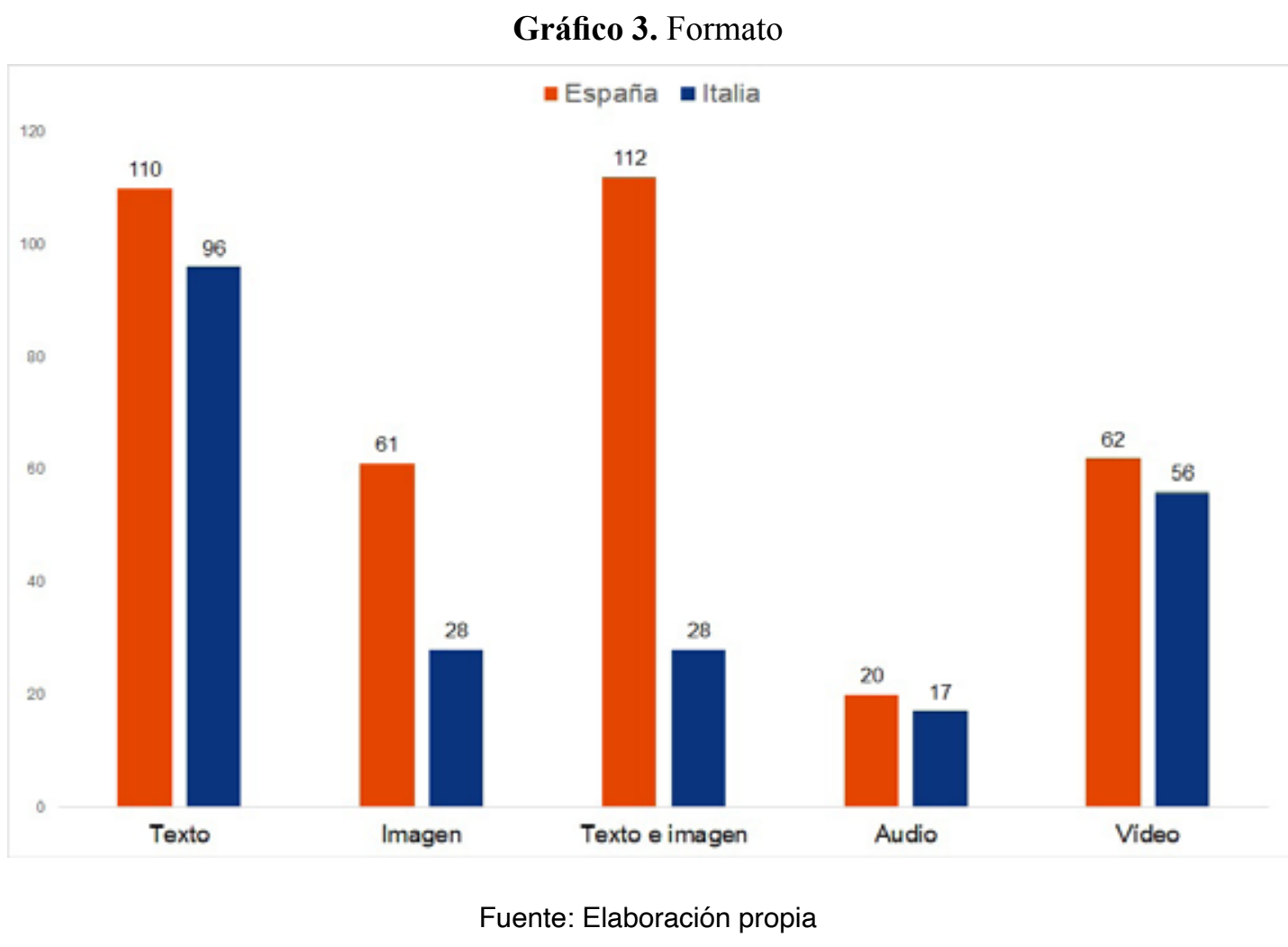

Revista de Comunicación, 2021, vol. 20, N¹. E-ISSN: 2227-1465 


\subsection{Cuarto elemento: temáticas generales}

La división temática presenta un total de seis categorías principales en el Gráfico 4, que fueron seleccionadas tras comprobar que eran los ámbitos que más se repetían en ambos países en un primer análisis realizado de forma general.

\section{España}

El primer tema comprende lo relacionado con las diferentes teorías del complot, que buscan colocar al ser humano como creador del virus con un objetivo macabro (Domínguez \& Amador-Bedolla, 2020). En el caso de España este primer tema no ha sido tan recurrente, representando solamente 22 de los 365 casos, un 6\% del total. La mayoría de estos casos surgen en las redes digitales, como por ejemplo aquellos que recogen que "el nuevo coronavirus fue patentado por la empresa Pirbright Institute en años precedentes" (Maldita.es, 4 marzo 2020) o, en el mismo sentido, "que la pandemia actual está siendo causada por un virus con inserciones, es decir, modificado en el instituto de virología de Wuhan" (Maldita.es, 14 marzo 2020), la ciudad china en la que se descubrieron los primeros casos de coronavirus.

Mucha mayor difusión han tenido en el país los contenidos sobre ciencia y salud, una categoría que recoge diferentes aspectos, desde informaciones erróneas o manipuladas sobre la gestión de la crisis sanitaria, falsos tratamientos para hacer frente a la enfermedad como alimentos o productos homeopáticos o bulos supuestamente elaborados por profesionales de la salud donde se indican, además, una multitud de datos de instituciones u organismos oficiales para dotar de cierta veracidad la información. Esta segunda categoría tuvo 84 casos identificados, lo que supone casi el 23\%.

En esta ocasión, nos encontramos con afirmaciones que aseguran que un médico llamado Zhong Nanshan habría recomendado "enjuagarse la garganta con agua salada ligera antes de ir al hospital u otros lugares públicos" (Maldita.es, 5 febrero 2020) con tal de no contraer el coronavirus. Vemos también otras donde se asegura que "China anunció oficialmente el éxito del suero cubano que el Dr. Hala, ministro de Salud de Cuba, presentó al Ministerio de Salud de China” (Maldita.es, 17 marzo 2020).

El principal tema que ha ocupado prácticamente la mayor parte de los casos está relacionado con la política nacional e internacional, lo que indica una fuerte politización de la pandemia COVID-19, sobre todo con ataques a la gestión del Gobierno central y los diferentes gobiernos autonómicos, como veremos posteriormente. De los 365 bulos totales, esta categoría registra 146 casos, un $39,90 \%$ del total. Entre ellos cabe mencionar, por ejemplo, la circulación por redes sociales digitales de imágenes de supuestos artículos de tirada autonómica donde se decreta el aislamiento de varios territorios (Maldita.es, 11 marzo 2020) o de ciertos comunicados del Gobierno central en el que se asegura que si "la suspensión de las clases en los centros de educación abarcara el periodo de exámenes, los mismos se darían por aprobados" (Maldita.es, 13 marzo 2020).

El cuarto tema, China como epicentro del virus, llama la atención porque los casos parecen concentrarse en las primeras semanas analizadas para después ir desapareciendo su propagación paulatinamente. Ello es debido, seguramente, porque, al notificarse los primeros afectados, esto provocó un señalamiento relacionado con el origen del virus. Los elementos identificados son únicamente 14 , un $3,82 \%$. De todos los casos analizados, sobresale un vídeo en el que se ve un mercado con animales en jaulas. Estas imágenes se difundieron y relacionaron con el brote del nuevo coronavirus iniciado en China y se afirmaba que "el lugar pertenecía al mercado desde el que supuestamente se propagó el virus". En realidad, se demostró que el vídeo no estaba grabado en China, sino en Indonesia y que es anterior a la llegada de la pandemia (Maldita.es, 29 enero 2020).

La siguiente categoría analiza las denominadas como cadenas falsas, que consisten en la difusión de bulos que aprovechan la coyuntura del virus para realizar estafas mediante enlaces con imágenes 
o textos llamativos que ofrecen dinero o productos bancarios. Este tipo de estrategias ha registrado una difusión notable con un total de 47 casos, el 12,84\%. Este tipo de contenido nos informa que "el Gobierno ha destinado un bono semanal para cada familia y que este dinero debe ser utilizado para comida y medicinas". Lo que nos pide es que compartamos el enlace con diez de nuestros contactos o grupos de WhatsApp para que así se siga difundiendo el mensaje. De esta manera, es posible que accedan a los números de teléfono de esos contactos (Maldita.es, 25 marzo 2020).

Un último grupo de otros se ha quedado reservado a aglutinar diferentes temáticas que por su cantidad no representaban una muestra lo suficientemente importante como para analizarse por separado, llegando a 52 casos, un $14,20 \%$ del total.

\section{Italia}

El primer tema analizado corresponde a las teorías del complot, donde en Italia ha alcanzado una elevada circulación, también porque en varios casos se han añadido a dietrologías ya consolidadas, difundidas por actores como el movimiento antivacunas NoVax y los detractores de la tecnología $5 \mathrm{G}$.

Las teorías del complot llegan a Italia incluso antes de que la pandemia comience a extenderse en el territorio nacional, pero alcanzan el pico de difusión en los meses de abril y principios de mayo. De la muestra analizada, 60 casos se asocian a la categoría del complot, representando un $26,66 \%$. Ya a finales de enero comenzaron a circular algunos de los temas que serán constantemente representados durante los meses siguientes: la creación artificial del virus, desarrollada por los representantes de Big Pharma con el fin de sacar provecho de la venta de la vacuna (Open, 25 enero 2020) o el origen de la epidemia en la fuga de material biológico de un laboratorio militar de Wuhan donde se estudian "armas químicas" (Open, 26 enero 2020).

La segunda categoría, ciencia y salud, contiene un amplio espectro de casos. Se registra una gran cantidad en las primeras etapas de la epidemia, principalmente debido al escaso conocimiento existente sobre el patógeno. Mucha resonancia tuvo el comentario de la viróloga María Rita Gismondo, que en un post en Facebook rebajó la gravedad de lo ocurrido, comparando la infección con una gripe común (Open, 24 febrero 2020).

Más tarde, en el apogeo de la emergencia, circuló una gran cantidad de noticias falsas a propósito de remedios y prevenciones: las dudas sobre la efectividad de las mascarillas y el distanciamiento social, los remedios homeopáticos y los tratamientos farmacológicos fueron los argumentos principales. Los remedios caseros se han vuelto muy populares, como demuestran las diversas falsas noticias sobre las propiedades curativas de abluciones en aceite de sésamo o de comer ajo (Open, 4 febrero 2020). En total, 51 casos pertenecen a esta categoría $(22,66 \%)$.

El tema que más actividad demostró fue el relativo a política nacional e internacional. Una gran cantidad de casos tenía como fin difundir falsas medidas gubernamentales, inventadas o manipuladas, con el objetivo de crear pánico o desacreditar la acción del Gobierno. Se evidencia un aumento repentino de este tipo de casos desde la segunda quincena de febrero, cuando aparecen los primeros afectados de COVID-19 en Italia, mientras que se puede observar una disminución a partir de mediados de abril. Una tendencia particularmente considerable en este caso ha sido la proliferación de imágenes de falsos decretos ministeriales reportando medidas inventadas, especialmente en materia de libertad de movilidad, apertura de las escuelas y asignación de fondos solidarios (Open, 27 febrero 2020 y Open, 19 abril 2020). Las noticias que tratan temáticas políticas fueron 76 , equivalentes al $33,77 \%$ del total.

El siguiente grupo incluye noticias que tienen que ver con China como epicentro del virus, lo que dio lugar a una ola de falsas noticias con tintes de racismo o denigración cultural. Alimentada por 
la incertidumbre hacia una enfermedad aún desconocida en Europa, esta categoría se concentró en el mes de febrero y luego disminuyó hasta agotarse en abril, así que su incidencia fue relativamente débil. Entre los 15 casos registrados (6,66\%), destacamos el vídeo falso de un mercado de animales de Wuhan, que presentaba imágenes grabadas en Indonesia (Open, 1 febrero 2020); también cabe mencionar la declaración ofensiva del gobernador de la región del Véneto, Luca Zaia, según la cual las ratas vivas forman parte de la dieta china (Open, 28 febrero 2020).

Se han encontrado números similares en relación con el tema de las cadenas falsas, donde la mayoría de los casos se trata de estafas, generalmente difundidas a través de WhatsApp, pero a menudo conectadas a través de un enlace a páginas externas que prometen ofertas especiales o ventas de varios tipos de productos. Se detectaron 14 casos $(6,22 \%)$, que van desde datos falsos hasta diferentes tipos de bromas, como en el caso del enlace transmitido a través de Whatsapp que promete 1.000 euros, lo cual, sin embargo, simplemente redirecciona a un gif animado (Open, 31 marzo 2020).

El último tipo, que agrupa todos los contenidos que no van ubicados en ninguna de las categorías anteriores, consta de 9 noticias. Este resultado corresponde a un porcentaje de menos del $4 \%$ del total.

Gráfico 4. Temáticas generales

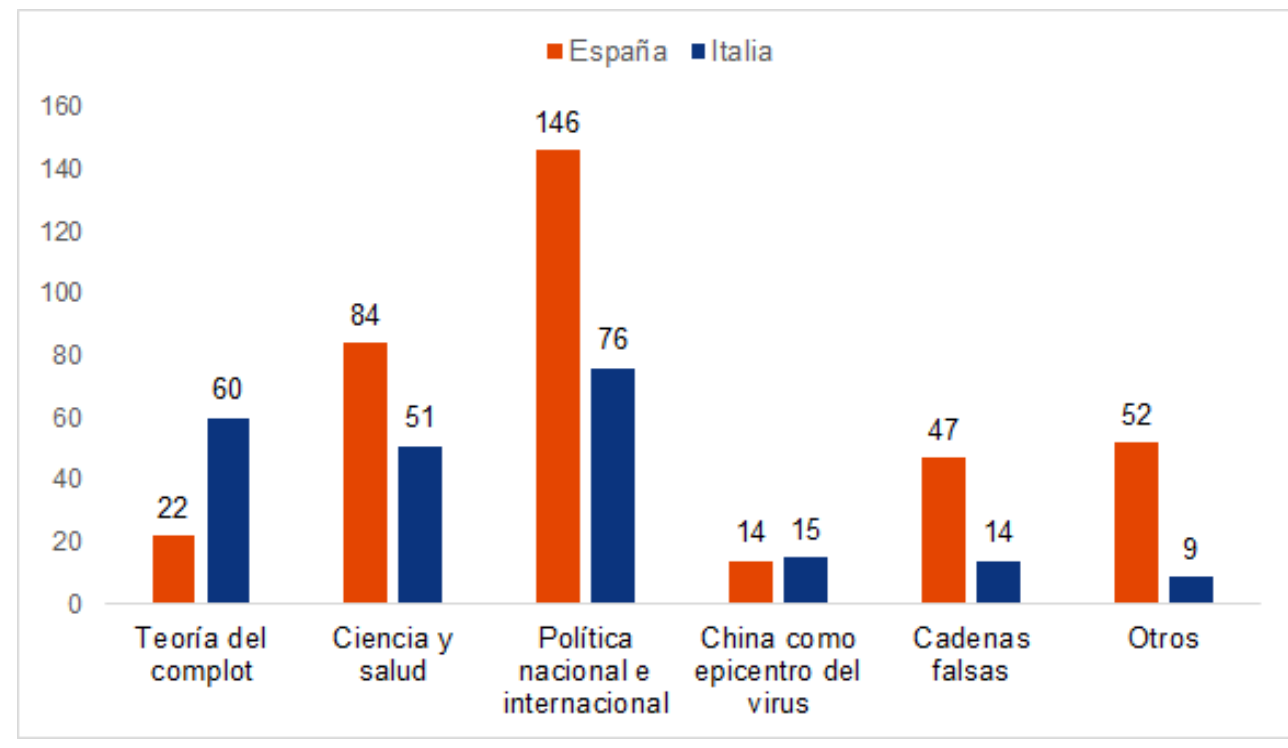

Fuente: Elaboración propia

\subsection{Quinto elemento: ejes discursivos}

En este último ítem se ha tratado de ser lo más específicos posible a la hora de analizar los principales ejes discursivos predominantes en los diferentes casos identificados. Para ello, cada una de las categorías que se han seleccionado contiene variaciones entre España e Italia, lo que ha posibilitado comparar el comportamiento y observar las diferencias en el tratamiento y difusión de los contenidos entre ambos países.

\section{España}

A diferencia de otras crisis de mayor intensidad y brevedad, como las de el Prestige, los atentados del $11 \mathrm{M}$ o el accidente del metro de Valencia, la del coronavirus en España forma parte de las denominadas como crisis de sombra alargada (long shadow crisis), en las cuales la influencia política y la agitación social están presentes durante un periodo que se extiende en el tiempo (Crespo, Garrido \& Medina, 2017). 
En este sentido, el campo político en España presenta diferencias respecto a otros países del entorno, sobre todo en cuanto a la unidad entre las diferentes fuerzas y el Gobierno. De hecho, en el país se ha experimentado el llamado blame game o juego de la culpa, donde las responsabilidades políticas de la crisis se han convertido en ataques cruzados entre los diferentes partidos de oposición y el Gobierno (Crespo \& Garrido, 2020).

Buena parte de los primeros ha intentado culpabilizar al segundo de improvisación e ineficacia ante la crisis (Minder, 2020), mientras que este, por su parte, ha basado su estrategia discursiva por un lado, en la defensa de la sanidad pública y, por otro, en señalar los recortes pasados en el sistema de salud.

Según un estudio realizado sobre la generación de bulos (Negredo, Amoedo, Vara-Miguel, Moreno \& Kaufmann, 2020), la mayoría de las personas españolas encuestadas (49\%) descarga sobre el Gobierno y el conjunto de representantes políticos el hecho de ser los principales responsables de la no existencia de una información correcta.

Lo anterior coincide con que los ataques al Gobierno central hayan sido los contenidos más difundidos en redes digitales y medios de comunicación en el período analizado del trabajo con un total de 63 , un $17,20 \%$ de los 365 identificados, lo que demuestra que ha sido el principal eje discursivo sobre el que ha pivotado la actividad durante la pandemia. Entre estos, existen casos paradigmáticos, desde ataques personales a miembros del Gobierno (Maldita.es, 23 marzo 2020 y Maldita.es, 24 marzo 2020) hasta medidas y decisiones atribuidas falsamente (Maldita.es, 26 marzo 2020).

En un contexto donde se tiene un elevado desconocimiento sobre el virus, la situación favorece la aparición de manipulaciones y errores en datos de organismos oficiales. Es probable que la alta difusión de este tipo de casos esté sujeta a la aceptación de la llamada "autoridad epistemológica" (Bochenski, 1974) de quien aparece citado en el mensaje, como pueden ser en este caso médicos y científicos o instituciones y organismos oficiales como la OMS o los diferentes ministerios de Salud de los países.

Posiblemente la mezcla de elementos reales (la fuente) con falsos (la información) propicia la propagación y hace más difícil detectar el engaño en este tipo de bulos (Salaverría et al., 2020). Para el caso de España se contabilizan 54 bulos de esta temática, un 14,75\% del total. Por ejemplo, encontramos casos donde se difunden falsos boletines oficiales del Estado con información directamente adulterada (Maldita.es, 3 abril 2020).

Durante el período de cuarentena se ha registrado un aumento del posible hackeo de datos personales a través de las redes, fundamentalmente WhatsApp, con métodos fraudulentos como el phishing, que consiste en la creación de sitios falsos de Internet mediante algún tipo de comunicación, promoción de producto o ayuda con la finalidad de estafar económicamente a la población (Maldita.es, 2 abril 2020). Hasta un total de 40 casos fueron identificados en esta categoría, el 10,92\%.

Aunque la división en varios ejes temáticos pretendía que los bulos se repartieran de forma regular entre las diferentes categorías que fueron seleccionadas, lo cierto es que encontramos una gran diversidad de bulos sobre la COVID-19. En el caso de España, entre los más numerosos, están también aquellos que se refieren a remedios y actuaciones no probadas científicamente con $35(9,56 \%)$ (Maldita.es, 27 marzo 2020), los casos que se identificaban como falsos con 31 (8,46\%) o la crítica e informaciones falsas dirigidas contra gobiernos autonómicos o locales con un total de $24(6,55 \%)$ (Maldita.es, 28 marzo 2020).

Sin embargo, otras categorías que en un principio podría pensarse que tuvieran una mayor repercusión no han tenido un impacto destacable según el estudio. Tal es el caso de la información falsa 
o descontextualizada como crítica contra la gestión sanitaria y Fernando Simón como responsable (Maldita.es, 11 mayo 2020) que, a pesar de las críticas iniciales (Costa-Sanchez \& López-García, 2020), solamente se cuantifican en este apartado 4 elementos $(1,09 \%)$.

También en este mismo grupo, que partía con mayores expectativas pero que finalmente no ha arrojado resultados tan altos, se encuentra la categoría que intenta buscar una intencionalidad en la creación del virus por parte del ser humano y la presencia de sectores antivacunas (Maldita.es, 19 mayo 2020). Un total de 19 bulos se contabilizaron para esta categoría $(5,19 \%)$ de los 365 analizados en el estudio.

Con menor relevancia aparecen categorías muy variadas, desde el señalamiento a China como epicentro del virus (19), la asociación a Bill Gates y su fundación como sospechosos creadores del coronavirus (4), diferentes sucesos extraños generados tras la aparición de la pandemia (11), la utilización de símbolos de España como ataque político (9), las protestas en el barrio de Salamanca en Madrid (5), episodios de racismo (6), bulos con contenido humorístico o de parodia (12), personas famosas o conocidas contagiadas por el virus (11), temas relacionados con la religión (2) y la categoría otros, que engloba una gran diversidad de temas muy individualizados y que no supusieron un número relevante (19) como para considerarse un grupo propio en el análisis.

\section{Italia}

El primer caso de contenido falso sobre el coronavirus se remonta al 21 de enero, una época en la que la pandemia aún no se percibía como un problema europeo y en los medios de comunicación al tema se le dedicaba poco espacio. El impacto en la exposición mediática comienza el 30 de enero tras la noticia en la que dos turistas provenientes de China fueron hospitalizados en Roma al resultar positivos por el virus. Como consecuencia de ello, al día siguiente el Gobierno italiano aprueba el estado de emergencia.

El 20 de febrero se registra el primer brote de infecciones en el norte del país y en poco tiempo se determinan las primeras medidas de contención: el 23 de febrero se cierran los municipios con casos activos, el 8 de marzo la región de Lombardía y dos días después se extiende a todo el territorio nacional. En estos primeros momentos la tensión es alta y proliferan, sobre todo, las noticias falsas sobre casos de positividad y brotes inexistentes (Open, 29 enero 2020), pero hay que destacar que es poco después cuando surge el negacionismo que rechaza el recuento oficial de los fallecidos (Open, 22 marzo 2020).

Durante el mes de marzo la atención hacia la epidemia crece enormemente (Papapicco, 2020) y al mismo tiempo se intensifica la cobertura de los medios. En una investigación publicada recientemente (Autorità per la Garanzia delle Comunicazioni, 2020) podemos observar que entre el 21 de febrero y el 22 de marzo los contenidos sobre el nuevo coronavirus alcanzan el $45 \%$ de la información total, mientras que entre el 1 de enero y el 20 de febrero el porcentaje rondaba el $4 \%$.

En cuanto a la comunicación del virus, debe subrayarse el intento del Gobierno de asociar la narrativa institucional con el aspecto técnico-científico creando un comité para ello. Sin embargo, la sobreexposición mediática, el dogmatismo de expertos y divulgadores y el desconocimiento alrededor del virus propicia que se produzcan contradicciones que influyen en la credibilidad de las autoridades científicas. De este modo, un informe de mediados de abril muestra que casi la mitad de los entrevistados (48\%) creía que la comunicación de científicos y expertos generó confusión (Observa Science in Society, 2020).

También por el lado político se produce una cierta sobrecarga de información (Grandi \& Piovan, 2020a), que, combinada con la pluralidad de fuentes (a menudo descoordinadas), alimenta dudas y 
malentendidos. El mismo informe de Observa Science in Society devuelve una fotografía clara de la relación entre la ciudadanía y las instituciones: en abril el 30,2\% de los entrevistados considera que la comunicación del Gobierno apenas es suficiente, mientras que el 17,3\% la clasifica como pobre. Todo esto ha favorecido la propagación de los bulos.

Por lo tanto, no es casual que, entre los casos analizados, el eje más recurrente ha sido el de las falsedades sobre medidas y decretos del Gobierno, las cuales, inventadas o presentadas de manera engañosa, a menudo para crear pánico e ira, buscan el descrédito del mismo (Open, 11 mayo 2020).

Este discurso comprende prácticamente casi la totalidad del período de emergencia, con mayor concentración en la fase de reapertura cuando la falta de claridad en la comunicación institucional se convierte en un terreno fértil para la generación de noticias falsas (Grandi \& Piovan, 2020a; 2020b). Un ejemplo de ello es el documento falso de la Questura de Roma que enumeraba las actividades recreativas prohibidas en la playa (Open, 24 abril 2020). Con 34 casos, este tipo representa el $15,11 \%$ de la muestra analizada.

A mediados de marzo, con el dramático aumento de las muertes en Italia, se produce una crisis de confianza también hacia el discurso científico. La tendencia a presentar como una verdad absoluta lo que todavía son hipótesis sobre la naturaleza del virus causa confusión en la sociedad (Reggio, 2020) e impulsa la proliferación de noticias falsas sobre remedios y prevención. En total se detectan 32 casos respecto a medidas no probadas científicamente (14,22\% del total), algunos de los cuales también se utilizan en el contexto de estafas, organizadas sobre todo on line. Un ejemplo es el caso de la empresa Citozeatec, que presentó sus productos vitamínicos como capaces de destruir el virus (Open, 4 abril 2020).

Por su parte, la incertidumbre estimula la propagación de teorías del complot (D’Amore, 2020), lo que se refleja en que este eje se extienda presentando la pandemia como una compleja operación destinada a enriquecer y beneficiar económicamente a ciertas compañías productoras de vacunas (Open, 29 abril 2020). La difusión de esta tesis probablemente esté relacionada con el enraizamiento del movimiento NoVax en Italia. Se contabilizan un total de 26 casos relacionados con la antivacunación $(11,55 \%)$.

Tampoco es casualidad que en este contexto aparezca ya el 22 de enero el nombre de Bill Gates, desde hace tiempo protagonista de varias teorías del complot. Se destacan 11 bulos (4,88\%) que se refieren directamente al creador de Microsoft como implicado en la propagación del virus, por ejemplo, según una conocida teoría conspirativa, con el objetivo final de reducir la población mundial para asegurar la regeneración sostenible del ecosistema de la Tierra (Open, 26 enero 2020).

Mientras, en 19 casos $(8,44 \%)$ se identifica la narración del origen artificial del virus, supuestamente creado en un laboratorio de Wuhan. La mayoría de estos contenidos se difunden en las primeras etapas de la pandemia (Open, 17 febrero 2020), pero se retoman posteriormente conectándose a varias teorías del complot.

Durante las etapas iniciales, en una situación en la que el debate científico se encuentra extremadamente abierto, la producción discursiva de los medios se concentra en la dimensión cuantitativa del contagio (Pedroni, 2020). El tema más habitual de esta categoría es el de los brotes inventados y los casos inexistentes (Open, 1 febrero 2020), de los cuales recolectamos 17 casos (7,55\%). También pertenecen a este grupo los contagios falsos de personajes famosos con 4 casos, representando el $1,77 \%$ del total.

Otros tipos de ejes discursivos han tenido menos difusión porque están vinculados a una circunstancia específica. Este es el caso de los relacionados con las infracciones durante la cuarentena, re- 
gistradas especialmente en los primeros días del cierre y en las vacaciones de Semana Santa, con 14 casos $(6,22 \%$ del total). En el mismo sentido encontramos las noticias falsas sobre la cultura china con 9 casos (4\%) (Open, 1 marzo 2020), respaldada por la creencia de que la pandemia se originó por malos hábitos alimenticios o de higiene del país asiático. Esta narración pierde credibilidad con el empeoramiento de la situación en Italia y más tarde en Europa.

En la última parte de la clasificación se encuentran tipos de casos muy diferentes. Respecto a la categoría de promociones falsas, se observaron 12 casos (5,33\%). El mismo porcentaje alcanzaron los contenidos sobre inmigración y su relación con la propagación del virus. Solamente $10(4,44 \%)$ son los episodios de conspiración que establecieron una relación entre el coronavirus y la tecnología 5G. Otras categorías encontradas son la manipulación de datos oficiales (5 casos), el sensacionalismo vinculado a eventos extraños o peculiares (5), la consideración del virus como una simple gripe (5) y capítulos explícitamente racistas (3). El último grupo, que comprende elementos que no pertenecían a las categorías anteriores, incluye 7 casos.

\section{Discusión y conclusiones}

Tras la comparativa realizada entre España e Italia para ver cómo han evolucionado los contenidos falsos durante la pandemia de la COVID-19, debemos constatar que el número de informaciones encontradas y analizadas en las diferentes plataformas de fact checking ha sido más numeroso en el caso español, con un total de 365 frente a 225 de Italia. Esta diferencia cuantitativa no ha impedido observar las características en cada uno de los elementos examinados.

En cuanto al primero de ellos, referente a los tipos de contenidos, si bien se contabilizan más casos en el ámbito español, se mantiene una proporción equilibrada entre ambos en el conjunto de categorías, destacando en los dos países la cantidad relativa a las mentiras o manipulaciones intencionadas. La misma tendencia se mantiene en el segundo grupo más numeroso, que corresponde a informaciones erróneas.

Sí que se aprecian diferencias más notorias en el segundo ítem, relacionado con los soportes de difusión. Mientras que España triplica a Italia en número de casos identificados en WhatsApp y le dobla si se suma el resto de redes digitales (Facebook, Twitter, Instagram y YouTube), el segundo supera al primero en redes y medios así como lo triplica en medios de comunicación. Observando sus números, España cuenta con una gran preponderancia en lo digital en tanto que el país transalpino muestra una distribución más multisoporte.

También existen variaciones en el tercero de los elementos, el cual tiene que ver con el formato. En el apartado español sobresalen dos categorías, que son texto y texto e imagen con números muy similares, situación que no se traslada al caso italiano, ya que destaca una categoría, que es el texto, seguida de un formato como el vídeo, que introduce un componente audiovisual diferenciador.

En lo que se refiere a las temáticas generales, pertenecientes al cuarto elemento, en ambos países los casos más numerosos corresponden a aquellos englobados en el campo de la política nacional e internacional, lo que demuestra que es el asunto más recurrente como ámbito de contenidos falsos. Cabe señalar también la etiqueta de ciencia y salud como segundo bloque en cantidad. La gran diferencia entre ambos radica en que en España se extiende más la difusión en las cadenas falsas mientras que en Italia son, en mayor medida, las teorías del complot.

Relacionado con lo anterior, el quinto elemento muestra los ejes discursivos más predominantes en cada uno de los países analizados. En España se concentran sobre todo en la información falsa o descontextualizada como crítica contra el Gobierno central y en la manipulación o errores en datos de organismos oficiales, lo cual deja entrever un componente de crítica institucional en ello. 
Por su parte, Italia coincide en un primer momento con las falsas informaciones sobre medidas y decretos del Gobierno, pero muestra la particularidad de unos contenidos centrados en remedios y actuaciones no probadas científicamente para prevenir la COVID-19 y también en la intencionalidad en la creación del virus y la defensa antivacunas.

En conclusión, aunque estos dos países comparten a priori estructuras similares en cuanto a los contenidos falsos en los temas más generales, al haber sido los dos primeros territorios y los más golpeados por la pandemia, así como por su proximidad geográfica, en este trabajo se ha podido constatar cómo existen ciertas diferencias notorias tanto en la forma como en los ejes discursivos sobre los que han pivotado los bulos y las noticias.

\section{Bibliografía}

Autorità per le Garanzie nelle Comunicazioni (2020). Osservatorio sulla Disinformazione Online: speciale coronavirus, 2. https://www.agcom.it/documents/10179/18281277/

Documento+generico+28-04-2020/0d954b13-72c8-4894-8ea3-fa9327f4e140?version=1.0

Bochenski, J. M. (1974). Was ist autorität? Einführung in die logik der autorität. Herder. [Trad. esp.: ¿Qué es autoridad? Introducción a la lógica de la autoridad. Herder, 1989].

Bracciale, R. y Grisolia, F. (2020). Information Disorder: acceleratori tecnologici e dinamiche sociali. Federalismi.it, 11, 58-72. https://www.federalismi.it/ApplOpenFilePDF. $\mathrm{cfm}$ ?artid=42112\&dpath=document\&dfile=23042020224311.pdf

Brennen, J. S., Simon, F. M., Howard, P. N. y Nielsen, R. K. (2020). Types, sources, and claims of Covid-19 misinformation. Reuters Institute for the Study of Journalism Factsheet, abril 2020, 1-13. https://reutersinstitute.politics.ox.ac.uk/types-sources-and-claims-covid-19-misinformation

Casero-Ripollés, A. (2020). Impact of Covid-19 on the media system. Communicative and democratic consequences of news consumption during the outbreak. El profesional de la información, 29 (2), e290223. https://doi.org/10.3145/epi.2020.mar.23

Costa-Sánchez, C. y López-García, X. (2020). Comunicación y crisis del coronavirus en España. Primeras lecciones. El profesional de la información, 29 (3), e290304. https://doi.org/10.3145/ epi.2020.may.04

Crespo, I., Garrido, A. y Medina, R. M. (2017). La comunicación de crisis en la Administración Pública española: análisis de evidencia empírica. Gestión y Análisis de Políticas Públicas, 18, 110-134. https://doi.org/10.24965/gapp.v0i18.10465

Crespo, I. y Garrido, A. (2020). La pandemia del coronavirus: estrategias de comunicación de crisis. Más Poder Local, 41, 12-19. http://maspoderlocal.es/files/articulos/coronavirus-estrategiascomunicacion-crisis-mpl41.pdf

D’Amore, M. (2020). Comunicazione, distanziamento e socialità ai tempi del coronavirus. Cambio. Rivista sulle trasformazioni sociali, OpenLab on Covid-19. https://doi.org/10.13128/cambio- 8456

Domínguez, L. y Amador-Bedolla, C. (2020). El origen de COVID-19: lo que se sabe, lo que se supone y (muy poquito) sobre las teorías de complot. Educación Química, 31 (2), 3-11. https:// doi.org/10.22201/fq.18708404e.2020.2.75461

Grandi, N. y Piovan, A. (2020a). Coronavirus: un contagio (anche) informativo. MicroMega, 3, 39-48. http://temi.repubblica.it/micromega-online/micromega-42020-dopo-il-virus-un-mondonuovo-presentazione-e-sommario/ 
Grandi, N. y Piovan, A. (2020b, 26 de marzo). I pericoli dell'infodemia. La comunicazione ai tempi del coronavirus. MicroMega online. http://temi.repubblica.it/micromega-online/i-pericolidell'infodemia-la-comunicazione-ai-tempi-del-coronavirus/

Kata, A. (2012). Anti-vaccine activists, Web 2.0, and the postmodern paradigm - An overview of tactics and tropes used online by the anti-vaccination movement. Vaccine, 30 (25), 3778-3789. https://doi.org/10.1016/j.vaccine.2011.11.112

Larson, H. J. (2020). Blocking information on COVID-19 can fuel the spread of misinformation. Nature, 580 (7803), 306. https://doi.org/10.1038/d41586-020-00920-w

Lazer, D. M. J., Baum, M. A., Benkler, Y., Berinsky, A. J., Greenhill, K. M., Menczer, F., Metzger, M. J., Nyhan, B., Pennycook, G. y Rothschild, D. (2018): The science of the fake news. Science, 359 (6380), 1094-1096. https://doi.org/10.1126/science.aao2998

López-Borrull, A. (2020). Fake news y coronavirus: la información como derecho y necesidad. COMeIN [en línea], 98. https://doi.org/10.7238/c.n98.2025

López-Pan, F. y Rodríguez-Rodríguez, J. (2020): El fact checking en España. Plataformas, prácticas y rasgos distintivos. Estudios sobre el Mensaje Periodístico, 26 (3), 1045-1065. https:// doi.org/10.5209/esmp.65246

Losada, R. (2020). Las fake news en las crisis de la sociedad digital. Más Poder Local, 41, 48-50. http://maspoderlocal.es/files/articulos/fake-news-coronavirus-sociedad-mp141.pdf

Mayo-Cubero, M. (2020). News sections, journalists and information sources in the journalistic coverage of crises and emergencies in Spain. El profesional de la información, 29 (2), e290211. https://doi.org/10.3145/epi.2020.mar.11

Minder, R. (2020, 7 de abril): Spain's Coronavirus Crisis Accelerated as Warning Went Unheeded. The New York Times. https://www.nytimes.com/2020/04/07/world/europe/spaincoronavirus.html

Muñoz-Machado Cañas, J. (2020). Noticias falsas. Confianza y configuración de la opinión pública en los tiempos de Internet. El Cronista, 86-87, 122-135. http://www.elcronista.es/ElCronista-n\%C3\%BAmero-86-87-Coronavirus.pdf

Negredo, S., Amoedo, A., Vara-Miguel, A., Moreno, E. y Kaufmann, J. (2020). Digital News Report (España) 2020. https://www.digitalnewsreport.es/

Observa Science in Society (2020). Gli italiani e il coronavirus. https://www.observa.it/gliitaliani-e-il-coronavirus-i-nuovi-dati-dellosservatorio/

Papapicco, C. (2020). Informative contagion: The Coronavirus (COVID-19) in Italian journalism. Online Journal of Communication and Media Technologies, 10 (3), e202014. https://doi.org/10.29333/ojcmt/7938

Pedroni, M. (2020). Narrazioni virali. Decostruire (e ricostruire) il racconto dell'emergenza coronavirus. Mediascapes journal, 15, 24-43. https://ojs.uniroma1.it/index.php/mediascapes/ article/view/16765/16121

Pérez-Curiel, C. y Velasco Molpeceres, A. M. (2020). Impacto del discurso político en la difusión de bulos sobre Covid-19. Influencia de la desinformación en públicos y medios. Revista Latina de Comunicación Social, 78, 65-97. https://www.doi.org/10.4185/RLCS-20201469 
Pulido-Rodríguez, C., Villarejo-Carballido, B., Redondo-Sama, G., Guo, M., Ramis, M. y Flecha, R. (2020). False news around COVID-19 circulated less on Sina Weibo than on Twitter. How to overcome false information?. International and Multidisciplinary Journal of Social Sciences, 9 (2), 1-22. https://doi.org/10.17583/rimcis.2020.5386

Reggio, F. (2020). La krisis del coronavirus. Una sfida inattesa per l'essere umano e le società contemporanee. Considerazioni filosofico-giuridiche. CALUMET. Intercultural law and humanities review, 10, 118-142. http://www.windogem.it/calumet/upload/pdf/mat_98.pdf

Sala, M. y Scaglioni, M. (a cura di) (2020). L'altro virus. Comunicazione e disinformazione al tempo del Covid-19. Vita e Pensiero. https://vitaepensiero.mediabiblos.it/archivio/Sala_Scaglioni_ ebook.pdf

Salaverría, R., Buslón, N., López-Pan, F., León, B., López-Goñi, I. y Erviti, M. C. (2020). Desinformación en tiempos de pandemia: tipología de los bulos sobre la Covid-19. El profesional de la información, 29 (3), e290315. https://doi.org/10.3145/epi.2020.may.15

Ufarte-Ruiz, M. J., Anzera, G. y Murcia-Verdú, F. J. (2020). Plataformas independientes de factchecking en España e Italia. Características, organización y método. Revista Mediterránea de Comunicación, 11 (2), 1-17. https://doi.org/10.14198/MEDCOM2020.11.2.3

Ufarte-Ruiz, M. J., Peralta-García, L., Murcia-Verdú, F. J. (2018). Fact checking: un nuevo desafío del periodismo. El profesional de la información, 27 (4), 733-741. https://doi.org/10.3145/ epi.2018.jul.02

Vosoughi, S., Roy, D. y Aral, S. (2018). The spread of true and false news online, Science, 359 (6380), 1146-1151. https://doi.org/10.1126/science.aap9559

Vázquez-Herrero, J., Vizoso, Á. y López-García, X. (2019). Innovación tecnológica y comunicativa para combatir la desinformación: 135 experiencias para un cambio de rumbo. El profesional de la información, 28 (3), e280301. https://doi.org/10.3145/epi.2019.may.01

Vizoso, Á. y Vázquez-Herrero, J. (2019). Plataformas de fact-checking en español. Características, organización y método. Communication \& Society, 32 (1), 127-144. https://doi. org/10.15581/003.32.1.127-144 